\title{
COR E SENTIDO: COMENTÁRIOS SOBRE LEITURA DE CHARGE EM REDES SOCIAIS.
}

\section{COLOR AND MEANING: COMMENTS ABOUT POLITICAL CARTOONS ON SOCIAL \\ MEDIA}

\section{RAMOS, Paulo Eduardo}

Doutor em Língua Portuguesa pela Universidade de São Paulo e pós-doutorado em Linguística pela Universidade Estadual de Campinas.

Docente do Departamento e do PPG Letras da Universidade Federal de São Paulo (UNIFESP)

e-mail: contatopauloramos@gmail.com

ORCID ID: https://orcid.org/0000-0002-9348-4176

\section{CARMELINO, Ana Cristina}

Doutora em Linguística e Língua Portuguesa pela Universidade Estadual Paulista "Júlio de

Mesquita Filho" (UNESP/CAr).

Docente do Departamento de Letras da Universidade Federal de São Paulo (UNIFESP).

E-mail: anacriscarmelino@gmail.com

ORCID: https://orcid.org/0000-0002-7576-0595

\section{RESUMO:}

A proposta deste artigo é demonstrar a importância da cor no processo de produção do sentido, em especial o humorístico. O estudo, que se configura como de caso, será aplicado a uma charge, gênero que tem como característica central a leitura crítica de fatos relacionados ao noticiário jornalístico. A análise tomará como base uma produção brasileira que abordou o episódio golden shower, exposto pelo presidente brasileiro Jair Bolsonaro em mensagens veiculadas por ele no Twitter durante o Carnaval de 2019, e a forma como ela foi lida por meio de comentários em redes sociais. O assunto será trabalhado de forma interdisciplinar, por meio da articulação entre teorias relacionadas à cor, à produção de sentido em textos humorísticos e a estudos linguísticos que abordam as interações em ambientes digitais.

Palavras-chave: Redes sociais. Comentário. Charge. Cor. Sentido. 


\section{ABSTRACT:}

The aim of this article is to demonstrate the relevance of the color in the meaning process. The study will be applied in a political cartoon, genre that has the critical reading of the news one of its central characteristics. The analysis will be based on one Brazilian production, that addresses the golden shower case, that was exposed by Brazilian president Jair Bolsonaro in messages posted on Twitter during the 2019 Carnival days, and the way it was read through comments on social media. The subject will be worked in a interdisciplinar way, through the articulation between theories related to color, the production of the meaning in humorous texts and linguistic studies that deal with interactions in digital environments.

Keywords: Social media. Comments. Political cartoon. Color. Meaning.

\section{CONSIDERAÇÕES INICIAIS}

A imprensa teve de se adaptar aos tempos digitais. Gêneros antes lidos exclusivamente no papel migraram para as telas dos vários suportes onde se pode acessar a internet. Uma das produções que passaram a conviver com esse novo cenário de circulação foi a charge. Tão vinculada à mídia escrita, ela também foi transposta para as versões on-line de muitos dos jornais brasileiros e replicada nas páginas das redes sociais de seus autores, alcançando um público ainda mais plural.

Essa transição, no entanto, não apagou o elemento nuclear da charge: o diálogo com os assuntos contemporâneos. Crítica e tendencialmente humorística, ela manteve esse traço, construído no país desde o século 19. Cavalcanti (2005) atribui o primeiro desenho de humor gráfico brasileiro a $O$ Carcundão, jornal publicado em Recife entre abril e maio de 1831. A imagem apresentava uma mistura de burro com homem, que quebra o que parece ser uma viga. O autor era anônimo.

Nos anos e nas décadas seguintes, outras publicações passaram a utilizar o recurso gráfico em diferentes partes do país, com frequência nitidamente maior. Os desenhos mostravam ora pessoas comuns, ora personalidades representadas de forma caricata. No fim de 1860, surge no Rio de Janeiro o primeiro jornal dedicado inteiramente a desenhos de humor: a "Semana Illustrada". A este se seguiram outros, como "Diabo 
Coxo" (1864-1865) e "O Cabrião" (1866-1867), que traziam trabalhos do ítalo-brasileiro Angelo Agostini, tido como um dos pioneiros dos quadrinhos e um dos autores mais representativos do humor gráfico no país (cf. MARINGONI, 2011).

No fim do século 19, os desenhos de humor já eram familiares aos textos produzidos pela imprensa tradicional. A publicação de trabalhos de humor gráfico migrou para os dois séculos seguintes e se consolidou, em termos de gênero, ao que entendemos contemporaneamente por charge. Atualmente, elas circulam entre os principais jornais do país, em geral em páginas de prestígio, como a dos editoriais, na "Folha de S.Paulo", ou na capa, caso de "O Globo", do Rio de Janeiro. E também nas respectivas versões digitais de ambos, processo semelhante ao de outros periódicos de notícias brasileiros, sempre repercutindo graficamente algum fato recente.

A relação da charge com o noticiário é tão umbilical que Arbach (2007) defende a inclusão dela entre os gêneros visuais do jornalismo, compondo o que o autor nomeou de fato gráfico. Para Romualdo (2000), ela é fruto de uma relação de intertextualidade com a notícia, aspecto que seria um de seus elementos nucleares e que seria pautado por dados verbais, visuais ou verbo-visuais. Caberia ao leitor a recuperação dessa informação para entender o texto.

A literatura sobre o assunto tende a ver nos políticos brasileiros os principais alvos das sátiras. Não por acaso as charges costumam aparecer nos cadernos de política ou nas áreas de textos opinativos dos jornais, onde ocorrem, em geral, as notícias e as análises mais importantes. Por isso, a caricatura (lida aqui como recurso de estilo) é vista por Romualdo como um elemento integrante da charge. É por meio dela que são caracterizados os personagens reais a serem identificados pelo leitor.

Embora se concorde que a tendência seja essa, a realidade mostra que qualquer fato pode ser alvo da crítica e do humor do chargista. Até mesmo um coelho, nos dias próximos à Páscoa, pode ser alvo de alguma situação cômica, para ficarmos em um dos inúmeros exemplos possíveis. Por isso, parece-nos mais apropriada a definição do gênero proposta por Riani-Costa (2001, p. 47), por ser mais ampla e menos centrada em quem ou no que exatamente será representado. Para ele, trata-se de um texto autoral e assinado, que apresenta "um desenho humorístico sobre fato real ocorrido recentemente na política, economia, sociedade, esportes etc.". Tal produção seria composta por elementos verbais (que podem aparecer ou não) e visuais (presentes obrigatoriamente). 
Sobre os aspectos visuais, há uma tendência, sempre que o assunto é trabalhado, de se privilegiarem as figuras, as imagens, deixando a cor em segundo plano. Um dos componentes do signo visual, ela costuma ser sombreada, quando não apagada, em análises que busquem explicar os mecanismos de produção do sentido em textos gráficos veiculados pela imprensa, entre os quais as charges se incluem. A proposta deste artigo é demonstrar o quão relevante a cor pode ser em alguns casos, a ponto de ser essencial para a compreensão de determinados textos multimodais, nome dado às produções que mesclam elementos de diferentes semioses (cf. CAVALCANTE et al., 2014).

Para isso, será feito um estudo de caso. O exemplo a ser trabalhado é o de uma charge relacionada ao episódio golden shower. A expressão, que alude ao fetiche sexual de uma pessoa urinar em outra, foi trazida à tona por meio de postagens veiculadas pelo presidente brasileiro Jair Bolsonaro durante os dias do Carnaval de 2019. Em charges da época, que se pautaram nessa notícia, o amarelo (que alude à cor da urina, forma de representar a prática de golden shower) teve papel fundamental no processo de produção do sentido que levava à leitura crítica e humorística do fato.

Será feita, inicialmente, uma análise específica da charge selecionada e de como a cor se torna elemento relevante para a produção do sentido dela. Num segundo momento, a discussão irá se centrar em como o texto multimodal foi efetivamente lido. Para isso, serão apresentados comentários de pessoas que tiveram contato com o trabalho gráfico em redes sociais do autor (Facebook e Instagram). A abordagem do assunto irá demandar uma articulação interdisciplinar entre teorias relacionadas à cor (cf. GRUPO $\mu$, 1993; GUIMARÃES, 2000, 2003; SILVEIRA, 2015), à produção de sentido em textos humorísticos (RASKIN, 1985; ATTARDO; RASKIN, 1991; RAMOS, 2011, 2015) e ao modo como se dão as interações realizadas em ambientes digitais, assunto que será observado em particular nas análises com olhares teóricos vinculados às práticas de letramentos on-line (BARTON; LEE, 2015) e a estudos do texto (ELIAS, 2014; ELIAS; CAVALCANTE, 2017).

\section{COR E SENTIDO}

Um dos trabalhos que ajudaram a detalhar teoricamente as características da cor é o do Grupo $\mu$ (1993). Os autores do estudo, ao proporem um "tratado do signo visual", partem da constatação de que as pesquisas sobre imagem produzidas até então tendiam a priorizar as 
figuras, deixando a cor em segundo plano. Para eles, uma produção como uma tela de arte, composta apenas por tintas vermelhas, configuraria um texto visual. Não haveria, por essa perspectiva, uma hierarquia entre os diferentes signos que formam os enunciados.

Os pesquisadores do grupo dividem os signos entre verbais e visuais. Estes seriam, na verdade, um rótulo, que agrega dois elementos: o icônico (as figuras) e o plástico (a cor, a forma e a textura). Cada um deles compõe, segundo os autores, uma unidade sígnica autônoma. Comecemos pelo signo icônico. Os autores defendem que ele não seria uma mera cópia do real, mas, sim, um objeto reconstruído, transformado com base nos elementos culturais de quem dele se apropriou.

Tomando emprestado um exemplo dos próprios autores, pensemos em uma mesa e uma nuvem. Ambas seriam reais. Agora imaginemos uma foto de uma nuvem e uma pintura daquela mesma mesa. As duas produções seriam representações modificadas do real, reconstruídas numa forma sígnica. O processo de transformação deveria assegurar um mínimo de características, de modo a garantir sua leitura e sua equivalência. Nesse contexto, o signo icônico teria um papel mediador, ficando entre o referente real e a maneira como foi representado por determinada pessoa. Como houve esse filtro, fala-se de reconstrução ou transformação do referente.

Esse processo de transformação poderia configurar uma composição sígnica mais fiel ao espetáculo natural - como os pesquisadores nomearam o real - ou mais distante de suas marcas centrais. Essas duas situações sintetizam o método desenvolvido pelo Grupo $\mu$ para a percepção das imagens: quanto maior a correlação com o real, menor a abstração e maior a legibilidade; na situação inversa, maior a abstração e menor e legibilidade. O contorno das figuras também ajudaria nesse processo de percepção, por compor os limites e, por consequência, a forma das imagens.

O signo plástico, segundo o Grupo $\mu$, mantém relações de significado e significante independentes, dissociadas da necessidade da figuração. O signo, como já comentado, seria aplicado aos conceitos de textura, forma e cor. Em cada um deles, os pesquisadores usam um método de análise, baseado em oposições. Uma parede, por exemplo, pode ser lisa ou áspera (variação de textura), larga ou reduzida (forma), mais escura ou mais clara (tonalidades de cor). O nível de detalhamento dessas características iria variar conforme o interesse no objeto a ser analisado. 
No caso específico da cor, interesse para esta discussão, as oposições estariam centradas em três variáveis ou cromemas: luminosidade, saturação e dominância (a cor que serve de base). Esses elementos estariam relacionados a aspectos expressivos. Já no tocante ao conteúdo, este seria depreendido por meio de relações externas ao enunciado sígnico. Uma delas, por exemplo, é a que convenciona a vinculação do azul e do verde ao rótulo de cores frias e do vermelho e do amarelo, por outro, ao de cores quentes. Outra seria a atribuição (também convencional) de predicações às cores, sejam elas quais forem.

Em outros termos: por essa perspectiva, a atribuição de sentido consiste em um processo bastante fluido e fortemente vinculado ao entorno do texto. Para os pesquisadores do Grupo $\mu$ (1993, p. 241), há situações de enunciados, inclusive, "que só funcionam em relação a situações ou realidades exteriores à mensagem ${ }^{1 "}$.

Esses significados podem ser produzidos por outros elementos dos enunciados (por exemplo, as formas, as texturas, o sujeito icônico), de modo que se torna quase impossível atribuir univocamente conteúdos às expressões cromáticas. É preciso aceitar que a imagem plástica não está codificada a priori e elege livremente suas determinações coloridas $^{2}$. (GRUPO $\mu, 1993$, p. 218)

Esse conteúdo externo a ser considerado para o sentido é o que Silveira (2015) nomeia de aspecto cultural e simbólico da cor, que seria um dos três vieses pelo qual ela poderia ser explorada (os outros dois são suas características físicas e fisiológicas, ou seja, como o olho a assimila em termos cromáticos). Para a autora, a significação é um processo que leva em conta o lado social, a percepção e a memória individual. O lado social são as informações e convenções do meio cultural em que a pessoa vive. A percepção é o modo como as pessoas associam as cores às formas dos objetos. A memória é a retenção da cor atribuída às imagens apreendidas e que ficam agregadas na mente dos seres por experiência.

Nas palavras de Silveira (2015, p. 118), "os observadores são diferentes em respeito a correlacionar objetos e significados, provocando diferentes maneiras de perceber o mundo. Por isso, a percepção do meio

\footnotetext{
" "... [hay enunciados] que sólo funcionam em relación con situaciones o con realidades exteriores al mensaje."

$2 \quad$ "Eses significados pueden ser producidos por otros elementos de los enunciados (por ejemplo, las formas, las texturas, el sujeto icónico), de manera que resulta casi imposible atribuir unívocamente contenidos a las expresiones cromáticas. Es preciso aceptar que la imagen plástica no está codificada a priori y elige libremente sus determinaciones coloreadas."
} 
ambiente difere de modo sistemático entre os diversos povos e culturas". Seguindo o raciocínio da autora, os sentidos simbólicos agregados à cor advêm de três processos: de sua construção cultural, compartilhada coletivamente por meio do uso; da concretização dessas acepções em dicionários específicos de cor; dos efeitos psicológicos nos seres humanos.

Tomando como base o "Dicionário das cores do nosso tempo", de Michel Pastoreau, creditado pela autora como um dos principais do gênero usados no mundo, ela elenca significados socialmente atribuídos às cores e possíveis efeitos psicológicos delas. No caso específico do amarelo, que será objeto de nossa análise, ele é visto como cor da luz, do calor, da prosperidade, da alegria, da mentira, da melancolia, entre outras possibilidades. Seus efeitos nos seres podem transitar por um espectro amplo, da percepção de esquentamento a melancolia e traição.

A vinculação da cor ao entorno cultural é também o roteiro teórico seguido por Guimarães (2000, 2003). O autor se vale de uma série de exemplos para demonstrar como um determinado conteúdo plástico pode adquirir outro sentido em determinada situação sócio-histórica. Um dos casos citados por ele (GUIMARÃES, 2000) foi o do ex-presidente Fernando Collor de Mello. Em agosto 1992, ele foi à TV para conclama a população a ir às ruas para defender acusações sobre seu governo, consideradas por ele caluniosas e motivadoras de desestabilização. Para isso, pediu que as pessoas se manifestassem com as cores verde e amarela, as que predominam na bandeira brasileira.

$\mathrm{O}$ resultado foi contrário. No domingo seguinte, o povo foi às ruas. Mas, em vez do verde e amarelo, as pessoas que se manifestaram usaram o preto. Ocorreu o inverso do que o então presidente queria. No lugar de apoio, obteve protestos contra ele. Segundo Guimarães, ocorreu uma mudança na atribuição do preto. Este deixou de ser uma cor culturalmente vinculada a trevas e morte para adquirir uma conotação oposta, mais próxima à luz (de esperança) e vida. Diante de um processo de impeachment, Collor renunciou ao cargo em dezembro daquele mesmo ano.

O diferencial do estudo de Guimarães é que ele procurou abordar o tema especificamente no campo da comunicação, por meio de aplicação em textos veiculados pela imprensa brasileira. Para ele, nessa forma de produção, a cor não pode ser dissociada de seu conteúdo, a ponto de propor o conceito "cor-informação" para se referir a ela nas várias funções que pode desempenhar na mídia: 


\begin{abstract}
Assim, considera-se a cor como informação todas as vezes em que sua aplicação desempenhar uma dessas funções responsáveis por organizar e hierarquizar informações ou thes atribuir significado, seja sua atuação individual e autônoma ou integrada e dependente de outros elementos do texto visual em que foi aplicada (formas, figuras, texturas, ou até mesmo sons e movimentos, como em produtos multimídia) (GUIMARÃES, 2003, p. 31).
\end{abstract}

Nas produções jornalísticas, o uso da cor estaria atrelado a determinadas intenções de quem a usa. Desse modo, uma determinada capa de revista com a palavra crise, com letras em vermelho, traria um sentido de perigo. Se as letras, por outro lado, fossem alternadas por verde e amarelo, poderiam conotar que a eventual crise se referia ao Brasil, posto que foram usadas cor de usa bandeira. "Em síntese", diz Guimarães (2003, p. 41), "é possível notar que uma cor pode nos informar sobre inúmeros fatos", o que só aumenta a responsabilidade do jornalista e dos profissionais que cuidam da parte gráfica da imprensa.

Nos três autores selecionados para esta exposição, percebem-se ao menos dois pontos comuns: uma busca em cunhar um tratamento teórico ao tema e a atribuição do contexto sócio-cultural no que se refere aos significados das cores. Compondo signos plásticos, como defende o Grupo $\mu$, elas teriam sua significação depreendida a partir da associação com experiências anteriores e armazenadas na memória, ao mesmo tempo em que são compartilhadas coletivamente por determinado grupo de seres.

Mesmo assim, determinados contextos específicos podem atribuir outros sentidos, como pontua Guimarães. Ainda segundo o autor, na imprensa ela adquire valores de informação, aspecto que se torna particularmente relevante para a análise das charges, gênero associado à notícia e aos conteúdos factuais. Como o caso do golden shower, envolvendo o presidente Jair Bolsonaro e cujos exemplos serão analisados a seguir.

\title{
CASO GOLDEN SHOWER
}

A expressão golden shower sintetiza o ato de a pessoa urinar no corpo do parceiro ou próximo a ele. Não se espera, portanto, que seja incluída na retrospectiva de final de ano das notícias envolvendo um presidente da república. Isso, no entanto, ocorreu no Brasil. Nos últimos dias de 2019, a imprensa recuperou o termo composto para relembrar 
o primeiro ano de mandato de Jair Messias Bolsonaro, iniciado em primeiro de janeiro. O caso remete ao Carnaval daquele ano. No dia 5 de março, uma terça-feira, data do feriado nacional, o presidente postou no Twitter um vídeo que mostrava uma apresentação pública, em um palco montado ao ar livre.

Na cena, um homem punha o dedo no próprio ânus e, depois, um colega de palco urinava sobre a nuca dele. Abaixo da imagem, gravada com um smartphone e colocada no ar às 20h08min, Bolsonaro registrou: "Não me sinto confortável em mostrar, mas temos que expor a verdade para a população ter conhecimento e sempre tomar suas prioridades. É isto que tem virado muitos blocos de rua no carnaval brasileiro" (conforme Fig. 1, mostrada a seguir). E finalizava pedindo que seus seguidores naquela rede social comentassem e tirassem suas próprias conclusões (na postagem, esta última palavra havia sido escrita equivocadamente, "conslusões").

\section{Não me sinto confortável em mostrar, mas temos que expor a verdade para a população ter conhecimento e sempre tomar suas prioridades. É isto que tem virado muitos blocos de rua no carnaval brasileiro. Comentem e tirem suas conslusões:}

Fig. 1 - Texto de postagem de Jair Bolsonaro no Twitter em 5 de março de 2019 Fonte: Bolsonaro (5 mar. 2019)

Dado o teor inusitado do vídeo, ainda mais veiculado por um presidente, o caso "viralizou", jargão usado no meio digital para indicar que determinado conteúdo passou a ser comentado e duplicado em abundância pelos usuários de redes sociais. Diante da repercussão e da menção ao nome da expressão usada para sintetizar aquele fetiche erótico, Bolsonaro voltou ao Twitter, no dia seguinte, e perguntou "O que é golden shower?" (ver Fig. 2). O questionamento foi veiculado às 
9h26min e ganhou ainda mais repercussão ${ }^{3}$, dentro e fora das redes sociais.

\title{
O que é golden shower?
}

\author{
$09: 26-6$ de mar de 2019
}

\subsection{Retweets 158.613 Curtidas 3.960}

\section{$37 \mathrm{mil}$ \\ $66 \mathrm{mil}$ \\ $159 \mathrm{mil}$}

Fig. 2 - Pergunta de Jair Bolsonaro postada em 6 de março de 2019

Fonte: Bolsonaro (6 mar. 2019)

A imprensa deu destaque ao assunto. Jornais, sites informativos, rádios e TVs expuseram em manchetes o fato de o presidente ter postado um vídeo "pornográfico", rótulo usado pelo portal "G1". O mesmo "G1" reportou que o caso foi noticiado fora do país por jornais como o norte-americano "The New York Times", o inglês "The Independent" e o francês "Le Monde".

Nas redes sociais, além dos comentários em si e dos compartilhamentos, houve produção de conteúdos humorísticos. Parte deles também constou em retrospectivas de 2019, elencando quais foram os memes (criações de cunho cômico que viralizam na internet) mais populares ao longo de 2019. O assunto também inspirou desenhistas de humor gráfico. Levantamento feito na época em jornais e no site "Charge Online", página que reúne diariamente charges veiculadas na internet e em jornais de todo o Brasil, permitiu a reunião de 23 trabalhos.

As charges abordaram o tema de dois modos distintos. Um grupo de nove trabalhos focalizou a apropriação que o presidente fez do Twitter e/ou o conteúdo inusitado produzido por ele na rede social. Os 14 casos restantes criaram situações em que a cor amarela exercia algum papel

3 A postagem de 5 de março de 2019 computava, cinco dias depois, 86.031 curtidas, 13.361 compartilhamentos daquele conteúdo e gerou 65 mil comentários. A do dia seguinte somou quase o dobro de curtidas (159 mil), cerca de cinco vezes mais compartilhamentos (66 mil), embora tenha havido menos comentários (37 mil). 
no processo de construção do sentido humorístico. Esse segundo grupo pode ser dividido em duas outras categorias de charges:

1. sem conteúdo verbal escrito, à exceção das informações paratextuais (principalmente a assinatura do autor): 3 casos (21,43\%);

2. com conteúdo verbal, explicitando a expressão golden shower (8 casos; $57,14 \%$ ) ou não ( 3 casos; $21,43 \%$ ).

Para a proposta deste artigo, interessa-nos em particular o primeiro grupo, o de charges compostas exclusivamente pelas modalidades visuais. Isso porque o foco da análise é justamente o detalhamento de como a cor pode ser relevante no processo de produção do sentido. $\mathrm{E}$, em textos compostos apenas pelos signos imagéticos e plásticos, a ausência do verbal demanda que a compreensão se centre somente nas demais modalidades, a cor entre elas. É o que nos levou à seleção do caso a ser trabalhado, mostrado a seguir, na Fig. 3:

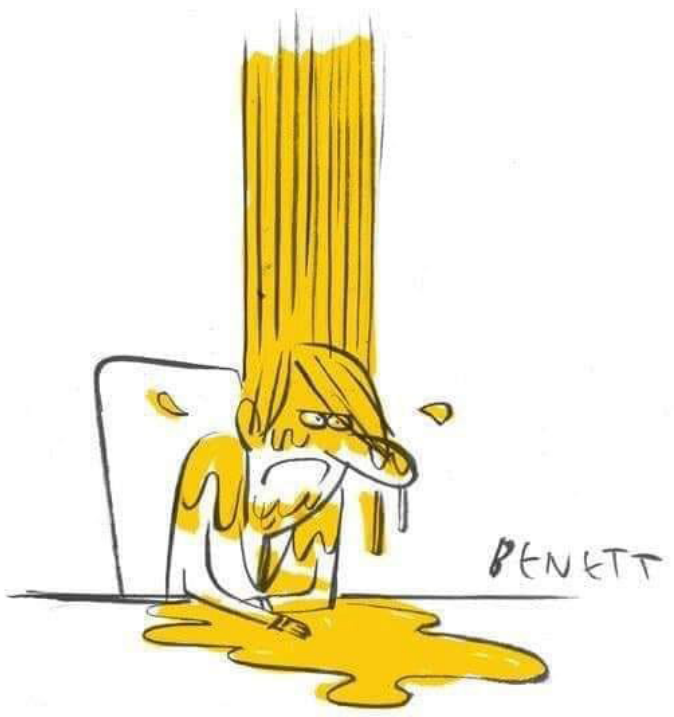

Fig. 3 - Charge de Benett

Fonte: Charge Online.(6 mar. 2019)

Essa charge, que irá compor este estudo de caso, foi publicada no site "Charge Online" em 6 de março de 2019, um dia depois do tuíte de Jair Bolsonaro. Ela também circulou no site de notícias "Plural" (BENETT, 
abr. 2019), um dos veículos de imprensa onde atua o autor, o paranaense Alberto Benett (ele também trabalha para o jornal "Folha de S.Paulo", onde produz uma charge semanal).

No desenho, reconhece-se que se trata do presidente brasileiro por meio da caricatura dele, que recria os traços de seu rosto, recurso recorrente no gênero, conforme exposto por Romualdo (2000). O político é mostrado sentado, sendo alvo de um jato líquido que cai por sua cabeça e escorre pelo restante do tronco. Sem forma muito definida, começa-se a depreender do que se trata por meio da cor amarela, que passa a ser associada à urina.

Essa vinculação entre cor (amarelo) e conteúdo de sentido (urina) só é possível se for levado em conta o momento em que a charge foi veiculada. A proximidade com o fato - o tuíte de Bolsonaro sobre o golden shower -, marca do gênero charge (cf. ROMUALDO, 2000; RIANI-COSTA, 2011), permite a leitura de que o presidente está tomando o tal "banho dourado" que a expressão em inglês conota. Pela feição como foi representado pelo desenhista, não demonstra ter gostado do resultado. É como se tivesse sido vítima do fetiche (literalmente, no caso) que ele mesmo trouxe à tona nos dias do Carnaval.

Vê-se que a cor amarela, um signo plástico, como postulado pelo Grupo $\mu$ (1993), adquire sentido próprio no contexto situacional em que foi utilizada. Nos termos de Guimarães (2000, 2003), ela adquire valor de informação. Expondo de outra forma: o sentido não seria possível não fosse observado esse aspecto sígnico, ancorado culturalmente. $\mathrm{O}$ entorno é recuperado - ou espera-se que seja - pelo leitor com base na associação entre o que vê e o fato envolvendo o presidente, testemunhado naqueles dias de Carnaval e vinculado à sua memória, tal qual defende Silveira (2015).

Para além desses apontamentos, cabe destacar também que, afora a assinatura do autor, Benett, mostrada no canto direito da imagem, tratase de uma charge construída apenas por meio de signos visuais (icônicos e plásticos). O sentido, portanto, é estabelecido apenas com o auxílio das figuras (representação caricata de Bolsonaro, paletó, cadeira e mesa, ambas parcialmente desenhadas) e das cores branca e, principalmente, amarela, entendida como urina por conta do entorno político da época.

$\mathrm{O}$ amarelo funciona, portanto, como o elemento que revela a quem lê a informação de que o líquido que cai na cabeça dele é um jato de urina, e não chuva ou água vinda de algum suporte específico (balde, mangueira ou outro). A cor exerceria o papel do que Raskin 
(1985) chamou de gatilho em sua teoria semântica baseada no humor (script-based semantic theory of humor, no original). A proposta era enquadrar piadas (principalmente) e outras produções semelhantes em um modelo teórico-metodológico comum, que ajudaria a explicar "as condições necessárias e suficientes para um texto ser engraçado, ou seja, uma piada" (RASKIN, 1985, p. 147, grifos do original).

O interesse declarado do estudo estava em produções humorísticas verbais. O elemento central para compreender o modelo pensando pelo pesquisador é a noção de script. O conceito, apropriado de áreas relacionadas à cognição, é definido como algo trazido mentalmente pelas pessoas e que responde à forma como elas reconhecem aspectos relacionados ao mundo, tanto os mais rotineiros e coletivos (tomar um ônibus, ir a um restaurante etc.) quanto os individuais, mais relacionados às experiências vividas e compartilhadas com os outros seres (onde e com quem trabalha, círculo de amigos, entre vários outros casos existentes).

Segundo Raskin, esses saberes - os coletivos e os individuais - seriam recriados nas narrativas cômicas ${ }^{5}$. As piadas trariam a particularidade de apresentar dois scripts que, embora diferentes e opostos, ainda que parcialmente, seriam compatíveis com aquele enunciado. Um deles seria verossímil (ou confiável) com a realidade de mundo como a conhecemos. O outro, ao contrário, traria uma situação inusitada, imprevisível (ou não confiável), e que seria revelada normalmente no final do relato, de modo a surpreender o ouvinte ou o leitor. Dessa inversão brusca de scripts é que surgiria o sentido humorístico.

O efeito obtido, para o autor, seria uma contradição ou uma ambiguidade ao que vinha sendo exposto até então na narrativa. Haveria um trecho-chave (punch line) que levaria à mudança do sentido, explicitando a situação cômica. Esse elemento - de ordem verbal, não custa reforçar - foi nomeado gatilho (trigger).

Posteriormente, Raskin revisou e modificou seu modelo teórico. Em parceria com Attardo (1991), desenvolveu o que chamou de teoria geral do humor verbal (general theory of verbal humor). O novo molde procurava ser aplicado a quaisquer produções humorísticas que apresentassem o elemento verbal, parcial ou totalmente. Em linhas gerais, a novidade foi a incorporação, de forma mais contundente, dos elementos pragmáticos e externos aos textos cômicos, como a existência de um propósito narrativo humorístico e a situação de circulação de

\footnotetext{
$4 \quad$ "... formulate the necessary and sufficient conditions for a text to be funny, i. e., a joke."

5 Embora reconheçamos que possa ser feita uma discussão sobre distinções entre os conceitos de "cômico" e "humor", trabalharemos ambos como sinônimos, por não ser o objetivo central deste estudo.
} 
tais produções. Vale ressaltar que o mecanismo dos scripts opostos foi mantido.

Embora mais amplo e com perspectivas interdisciplinares, o modelo ainda se restringia aos aspectos verbais - o que fugiria do caso da cor amarela, aqui analisada. Uma possível ampliação foi pensada por Ramos $(2011,2015)$, que procurou pensar a questão em tiras cômicas, produções compostas por elementos visuais e verbais e que ainda figuram entre os gêneros veiculados nos cadernos de cultura da imprensa brasileira. $\mathrm{O}$ autor partia da hipótese de que as tiras apresentavam mecanismo textual semelhante ao das piadas no processo de produção do humor.

Na pesquisa, ele incorporou as premissas centrais do pensamento de Raskin às de outros autores que haviam pensando a comicidade em piadas, como os de Gil (1991), Possenti (1998) e Muniz (2004). Em sua leitura, havia um ponto comum entre os trabalhos: a presença de uma situação inesperada nas narrativas, que levava ao sentido cômico. Essa quebra de expectativa se assemelhava à mudança de scripts, em particular pela presença de um elemento que permitiria a inversão de uma leitura (confiável) para outra (não confiável e surpreendente).

A diferença é que conteúdos de ordem visual - e não apenas os verbais - também poderiam funcionar como gatilhos para explicitar o conteúdo inesperado. O mecanismo, segundo postula Ramos, é semelhante ao das piadas. Tanto estas quanto as tiras cômicas apresentam narrativas curtas, compostas por personagens regulares ou não, que apresentam um desfecho inesperado, tendencialmente no final da história, que leva ao humor. Como se trata de outro gênero, com diferentes modalidades, os recursos que conduzem à inversão narrativa podem ser tanto de ordem verbal quanto visual.

Entendemos que esse método de explicação do processo de construção da comicidade em piadas e tiras cômicas possa ser aplicado também a outras produções do chamado humor gráfico, como as charges, gênero trabalhado neste artigo. Retomando o caso apresentado, o amarelo exerceria o papel de gatilho para evidenciar o script associado a fetiche sexual (materializado pelo golden shower, depreendido por meio da cor), oposto ao de chuva. Se, para a produção do humor, deve ocorrer uma mudança de script, tal qual defendem Attardo e Raskin (1991), e se esse mecanismo pode ser replicado a produções multimodais, como a charge, vê-se que o mecanismo pôde ser aplicado no caso da Fig. 3.

Vê-se que a cor é elemento relevante para a compreensão do sentido e do humor proposto pelo autor da charge. O que se poderia 
acrescentar à discussão é se as pessoas que tiveram contato com esse texto multimodal também tiveram leitura nessa direção. É algo que não é muito preciso de se aferir, posto que demandaria um estudo específico de recepção. Mas algumas sinalizações nesse sentido podem ser aferidas por meio das redes sociais. Embora os sites "Charge Online" e "Plural" não tivessem espaço dedicado a comentários dos usuários, Facebook e Instagram têm. O comportamento de quem se manifestou nessas duas redes sociais pode indicar um caminho para aprofundar a questão.

\section{REAÇÕES À CHARGE}

Uma das características da chamada Web 2.0 é a interatividade. Leitores das postagens de redes sociais se tornam, também, autores de conteúdos, manifestados por mensagens enviadas diretamente aos mantenedores das páginas (em caráter reservado) ou explicitadas no espaço dedicado aos comentários (e, portanto, públicas). Estes são definidos por Elias e Cavalcante (2017, p. 328) como:

um texto que, produzido no espaço da rede social, se insere numa relação com outros textos produzidos por outros usuários, cuja compreensão demanda que se leve em conta o espaço mesmo da rede e de sua forma de funcionamento, que pressupõe conexões múltiplas entre textos.

Essa profusão de textos e interações no espaço da rede social acarreta, segundo Elias (2014), uma poliautoria (diferentes pessoas compartilham a produção dos conteúdos) e uma poligenericidade (presença de diferentes gêneros utilizados e compartilhados pelos usuários). Para isso, o usuário precisa ser letrado digitalmente no mecanismo existente na rede social e também dominar diferentes modalidades, que se fazem presentes em muitas das manifestações. Na leitura de Brandon e Lee (2015, p. 33), as "pessoas mobilizam recursos semióticos disponíveis para construir sentido e afirmar suas relações com os significados expressos. Em particular, elas combinam imagens e outros recursos visuais com a palavra escrita online".

Os dois autores defendem também que, nesse processo de combinação de modalidades cristalizado no espaço dos comentários, as pessoas sinalizam uma postura, uma tomada de posicionamento a respeito do tema proposto na rede social. Para eles, comentar é "um elemento fundamental da adoção de postura em muitos sites populares 
da Web 2.0" (BRANDON e LEE, 2015, p. 49-50). "Nestes sites", dizem, "a postura não é adotada por um único falante ou escrito, mas é constantemente criada e renegociada de forma colaborativa por um público em rede" (BRANDON e LEE, 2015, p. 50).

Como mencionado, o autor do desenho (Fig. 3, Alberto Benett, tem atuação tanto em jornal impresso ("Folha de S.Paulo", onde publica uma vez por semana) quanto em ambiente digital (veicula uma charge diária no site de notícias "Plural"). É comum ele, depois, replicar os trabalhos em suas redes sociais - e também na página "Charge Online", onde foi identificada pela primeira vez a arte que compõe este estudo de caso.

No dia 6 de março de 2019, Benett reproduziu a charge sobre o golden shower em seus perfis do Facebook e do Instagram. Na primeira, limitou-se a expor o desenho, sem acompanhamento de nenhum registro verbal, à exceção dos dados paratextuais já existentes em cada uma das redes sociais (como o nome do perfil usado pelo autor, a data e a quantidade de comentários e compartilhamentos que o conteúdo recebeu); na segunda, além dos elementos paratextuais, inseriu algumas hashtags, recurso verbal e plástico que será trabalhado mais detalhadamente no próximo tópico.

Comecemos pelo Facebook. A postagem com a charge foi reproduzida na Fig. 4 (por questões éticas, os nomes e as fotos de quem acessou o perfil do desenhista e se manifestou na página foram apagados digitalmente com cor vermelha):
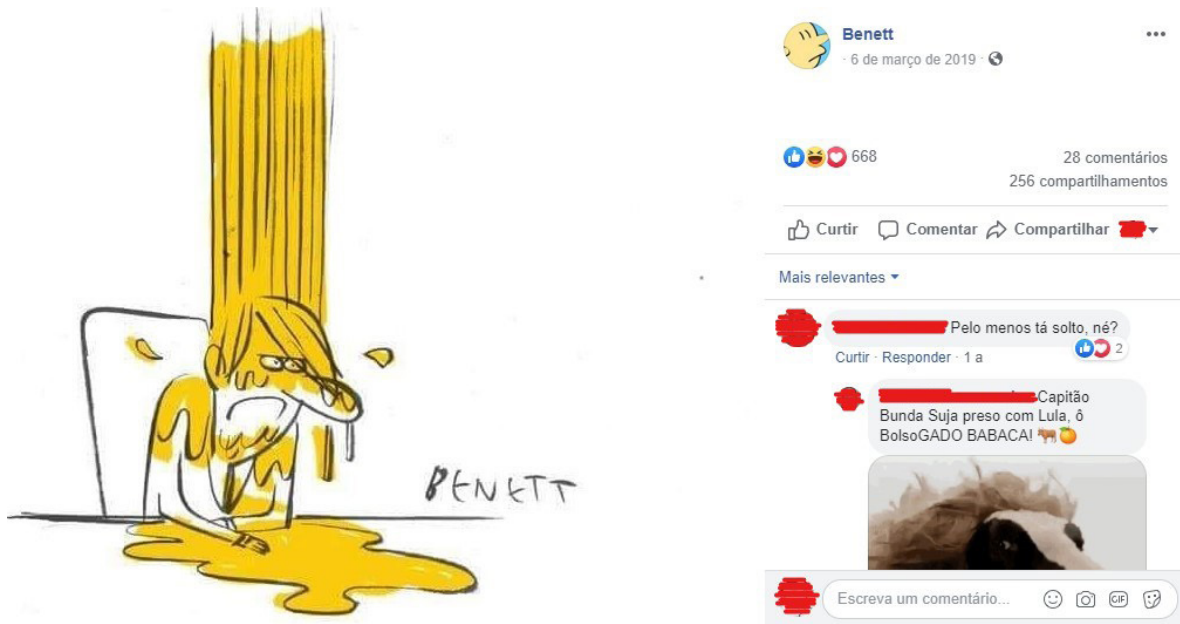

Fig. 4 - Postagem de charge no Facebook Fonte: Benett (6 mar. 2019) 
A postagem obteve 668 curtidas, 256 compartilhamentos (reproduções daquele conteúdo no perfil do próprio leitor) e 28 comentários $^{6}$. Na internet, a quantidade dessas manifestações serve como uma espécie de medidor da repercussão da postagem, funcionando como um feedback do conteúdo. Quanto mais tiver, maior será a difusão nos meandros daquela rede social (e, não raras vezes, fora dela também). Aqui, irão interessar os registros deixados pelos interlocutores no espaço dos comentários.

Dos 28 textos ali expostos, eles abordaram diferentes temas, nem todos especificamente sobre o conteúdo da postagem. Isso, aliás, é um procedimento recorrente entre os comentários da internet. Oliveira (2013), em análises de manifestações de leitores em blogs, defende que, no tocante à finalidade, as manifestações apresentam variados focos temáticos. Os textos podem abordar o assunto da postagem, manifestar uma resposta tanto ao autor quanto a outro leitor ou então expor um complemento (ou mesmo uma correção) ao que fora colocado no ar.

Parte dos comentários se deteve em elementos temáticos apresentados na charge ou por ela sugeridos, compondo a poliautoria descrita por Elias (2014). Um grupo explicitou divergências políticoideológicas com relação ao presidente caricaturizado no desenho, alguns defendendo o político, outros criticando. Houve registros de associação de Bolsonaro a um esquema de desvio de verbas destinado a campanhas eleitorais (este caso será comentado mais detalhadamente no próximo tópico, por propor outra leitura da charge). Muitos expuseram respostas a outros leitores, marcando os nomes de pessoas para que fossem avisadas daquele conteúdo quando acessasse a rede social.

Este último recurso está diretamente vinculado à cor. Isso porque, ao escrever o nome de outro usuário do Facebook, os caracteres ficam automaticamente azulados (indicador de que foram "linkados", como se diz no jargão da internet). Trata-se de um mecanismo previsto pela própria rede social para indexação do conteúdo a outro leitor, como se fosse um aviso para que acesse aquela informação. O recurso, que mescla elementos verbais com plásticos, foi identificado em $10(35,7 \%)$ dos 28 comentários

Ao todo, foram vistos 14 casos (50\%, metade, portanto) de registros que se valeram concomitantemente das modalidades verbal e visual (além da cor, perceberam-se situações em que imagens foram inseridas no final das frases). Houve 12 (42,9\%) ocorrências de manifestações 
somente verbais e duas $(7,1 \%)$ com links para produções exclusivamente visuais, caracterizando a multimodalidade (cf. BRANDON; LEE, 2015) e a poligenericidade (cf. ELIAS, 2014).

Uma dessas produções era um clipe da banda Turba, que se autodescreve em sua página do Facebook como sendo produtora de "Rock'n Roll clássico e minimalista, vagando pelo Psicodelismo Sombrio". O título da canção indexada pelo comentário é relevante para esta análise: "Mija em mim". A exibição mostra um homem na cama e, acima dele, uma mulher, que pratica golden shower (nada mostrado explicitamente no vídeo, mas sugerido por meio dos pingos e jorros que caem sobre o corpo e a boca dele).

O início da letra já reforça essa interpretação: "Mija em mim / Quero sentir seu gosto / Mija em mim / Abençoa o meu corpo / Mija em mim / Batismo que eu sempre quis". Ou seja, a pessoa que se lembrou da música e a inseriu no espaço dos comentários leu previamente a charge, entendeu que ela fazia referência ao episódio protagonizado pelo presidente da República naqueles dias de Carnaval e compartilhou o vídeo com os demais seguidores de Benett. Em outros termos: o leitor produziu sentido a partir da cor (que se torna informação, como postula GUIMARÃES, 2000, 2003) explicitada no desenho.

Reitera-se: isso se deu por meio da depreensão dos signos imagéticos e plástico e do complemento das informações sugeridas pelo desenho (que se tratava de Bolsonaro, que a referência era ao episódio do golden shower, que o político havia abordado o assunto no Twitter naquele feriado, que se extraía humor a partir do fato, marca do gênero charge), depreendidas a partir do contexto cultural da época (cf. SILVEIRA, 2015). Há registros de outros leitores que explicitavam ter feito interpretação semelhante. Três pessoas escreveram onomatopeias (grafadas da maneira própria à convencionada pelos usuários de redes sociais) que indicam riso:

- "hahahahahahahahahaahahahahaha" (neste caso, a pessoa acrescentou o a frase "rindo demais";

- "hahaha";

- "kkkk".

Infere-se que, se explicitaram risos, leram e provavelmente entenderam que a charge postada procurava produzir um sentido humorístico e que ele se deu, em grande parte, pela presença da cor amarela. Houve um quarto registro de onomatopeia indicadora de 
comicidade, "kkkk", mas, na frase onde foi redigida, sugeria mais crítica e ironia ao desenhista. O seguidor escreveu: "Aí, nossa, que desenho engraçado... Aí nossa, ele é crítico, nossa que gênio... kkkk...". Foi desse modo, pelo menos, que foi lido por uma usuária da página. Ela saiu em defesa do cartunista, com esta resposta: "Mas... Ele é mesmo (?). Inclusive é pago por suas sátiras, diferente de quem não conhece e fala bosta". E finalizou com um desenho digital de uma pessoa com os braços erguidos. Vê-se que, como descrito por Oliveira (2013), ocorreram respectivamente respostas tanto de leitor para autor quanto de leitor para leitor.

Outra pessoa também explicitou ter vinculado a charge - e a cor mostrada por ela - ao episódio do golden shower. Ela registrou no comentário o neologismo "impixixi", termo composto, criado a partir de uma redução de "impeachment" ("impi") e "xixi". Oralmente, a pronúncia do " $\mathrm{x}$ " guarda semelhança com o "ch" da expressão inglesa, que remete ao processo de retirada de um político do cargo para o qual foi eleito). Seria, na prática, a demonstração de um desejo de que Bolsonaro saísse do cargo por conta do envolvimento com o episódio postado no Twitter durante aqueles dias de Carnaval.

\section{OUTRA LEITURA DA COR}

Nas duas situações de uso de recursos estritamente visuais, os dois casos reproduziram links para vídeos. Quando isso é feito, um determinado momento do vídeo fica congelado no espaço reservado ao comentário. Basta clicar nessa imagem para rodar a sequência. Um deles era um gif, sigla de graphics interchange formats, recurso usado para reproduzir uma cena curta repetidamente (pode ser um desenho criado por computador, um trecho de filme ou de animação, entre outras possibilidades).

No caso, foi apresentada uma animação digital com um grupo de laranjas rolando, como se estivesse ocorrendo uma avalanche delas. As Figs. 5 e 6, reproduzidas a seguir, captam dois momentos distintos do gif, que permitem visualizar melhor como foi construído o movimento, visto do ponto de vista do leitor. 

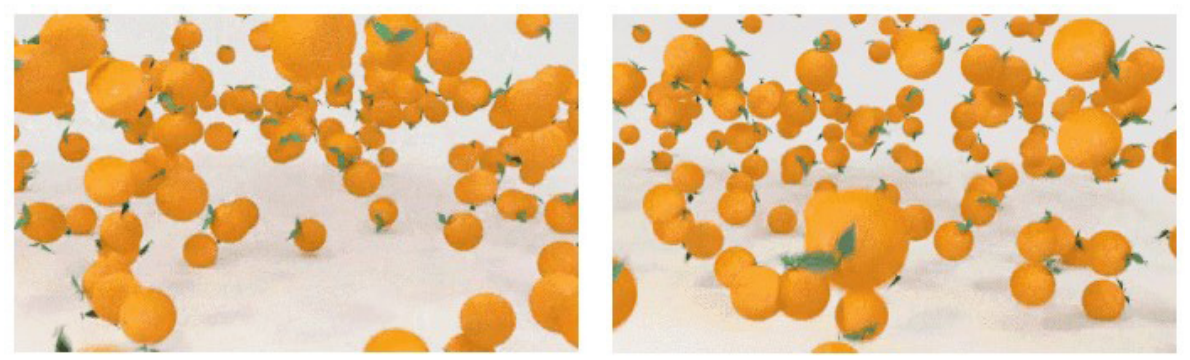

Figs. 5 e 6 - Gifs com animação de laranjas rolando

Fonte: Media 1. Tenor (06/03/2019)

Esse gif é relevante para a análise porque ele materializa uma interpretação da charge distinta da apresentada anteriormente. A pessoa que inseriu a animação no comentário havia feito, logo acima, um outro registro, este de ordem verbo-visual. Ela digitou esta frase (reproduzimos a mesma escrita, com os mesmos sinais gráficos): "Capitão Bunda Suja preso com Lula, ô BolsoGADO BABACA!". Ao trecho, incluiu, ao final, duas imagens pequenas, quase do mesmo tamanho das letras maiúsculas, a de um boi e a de uma laranja (Fig. 7, mais adiante).

Quem teve contato com esse comentário precisou completar muitas das informações ali presentes. "Capitão" é uma referência à patente de Bolsonaro de quando deixou o Exército, no final da década de 1980. A predicação "bunda suja" conota um viés pejorativo ao exmilitar que, segundo o autor do comentário, teria envolvimento em situações de corrupção (estaria "sujo", portanto). O mesmo ocorreria com o ex-presidente brasileiro Luís Inácio Lula da Silva (como exposto no trecho "preso com Lula", que, naquele momento (março de 2019), ainda estava preso pela acusação de corrupção passiva e lavagem de dinheiro (o político foi solto em novembro do ano seguinte).

A expressão "bolsogado" seria uma forma pejorativa de se referir a quem então seguia quase cegamente Jair Bolsonaro nas redes sociais. $\mathrm{O}$ termo é formado pela aglutinação do sobrenome do presidente ("bolso") com o substantivo "gado". Isso explicaria a presença de uma imagem de 
boi (textos compostos por diferentes modalidades) ao final da frase e de outro gif (poligenericidade), incluído logo abaixo do mesmo comentário, que mostra um bovino, com cabelos esvoaçantes, acompanhado do logo utilizado durante a campanha eleitoral pelo então candidato à Presidência da República, com os dizeres alterados para "Eu sou gado do Bolsonaro":

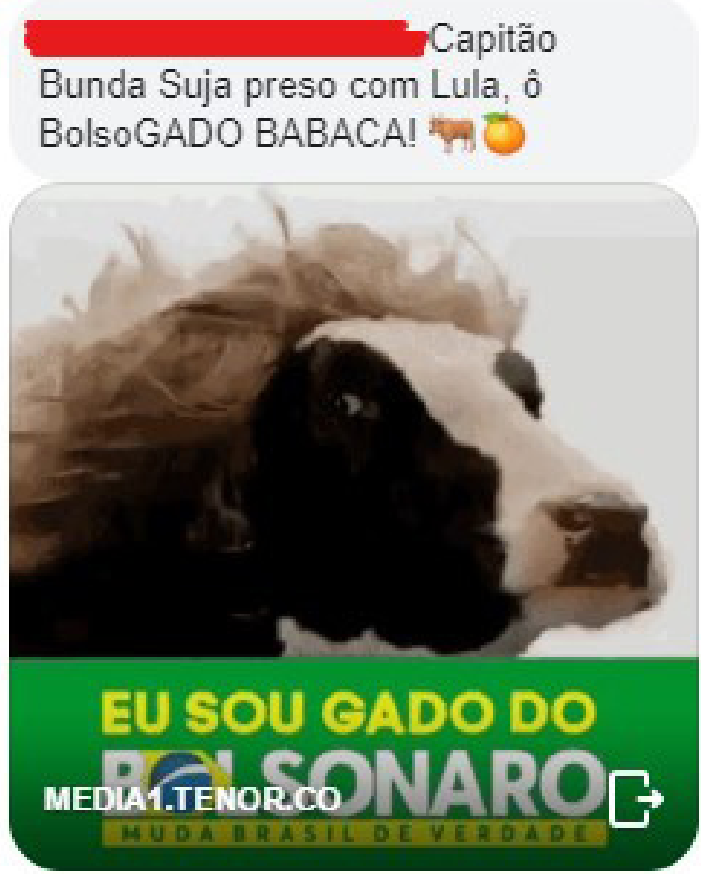

Fig. 7 - Comentário de leitor registrado no Facebook

Fonte: Benett (06/03/2019)

A exposição ainda não explica a presença da laranja, cuja explicação passa necessariamente pela cor. Uma vez mais, deve-se apoiar na memória do leitor e nas inferências realizadas por ele. Em fevereiro de 2019, um mês antes do Carnaval e do caso golden shower aqui analisado, o jornal "Folha de S.Paulo" revelou um esquema de desvio de verbas do fundo eleitoral, identificado em Minas Gerais e Pernambuco (MATTOSO et al., 4 fev. 2019; BRAGON; MATTOSO, 10 fev. 2019). Inicialmente destinado a candidatos ao cargo de deputado, o dinheiro era usado por outros políticos do partido, o PSL (Partido Social Liberal), o mesmo do presidente Jair Bolsonaro. 
Em outros termos: pela denúncia, os candidatos atuavam como "laranjas", gíria utilizada para definir a "pessoa que substitui outra em muitas situações" (SERRA E GURGEL, 1998, p. 288). O termo, inclusive, foi usado nas manchetes das reportagens que revelaram a fraude. O episódio gerou uma cena inusitada: um protesto na Câmara dos Deputados, em que congressistas da oposição portavam a fruta nas mãos e usavam aventais alaranjados.

Esse caso foi o lido pelo autor do comentário registrado no Facebook, e não o do golden shower. A associação ao esquema dos laranjas foi feita por meio da cor. O internauta enxergou suco de laranja no jorro que caía sobre a cabeça de Bolsonaro na charge criada por Benett. Se foi feita, não se pode dizer não se trata de uma leitura possível e, por isso mesmo, cabe ser discutida.

Dois dos cromemas da cor, como detalhado pelo Grupo $\mu$ (1993), são a luminosidade e a dominância. Esta, para ser associada ao episódio dos desvios do fundo partidário, foi lida como predominantemente amarela; aquela, como sendo de tonalidade mais escura. Essa interpretação também estaria ancorada no contexto sócio-histórico e cultural da época e dialogaria com outra notícia, veiculada no mês anterior. De todo modo, manteria uma das marcas do gênero charge, que é a abordagem de algum fato jornalístico contemporâneo.

Do ângulo de produção do humor, seria o amarelo escuro que exerceria o gatilho para a mudança de script: de tomar chuva, muda-se para um jorro acentuado de suco de laranja (um script de tomar suco ou de se servir da bebida). A cor é que permitiria essa leitura que, como visto, é diferente da vista até então e que se afasta do caso do golden shower. Qual é correta? Do ponto de vista analítico-descritivo, as duas, já que ambas foram efetivamente feitas.

Esse assunto foi, inclusive, abordado em trocas de mensagens nos comentários da postagem. Um leitor perguntou se era "suco de laranja ou golden shower". Teve uma resposta direta e outra, mais ao final da postagem. A direta: "uma mistura...", sinalizando que Bolsonaro poderia ter sido vítima de um jorro dos dois casos. A resposta ao final da postagem: um usuário da rede social reproduziu a tela do Twitter em que o presidente pergunta "o que é golden shower?" e, dessa forma, sustenta com maior propriedade seu ponto de vista a respeito.

Outra questão que poderia ser feita é qual seria a intenção do autor, com qual notícia ele teria pretendido dialogar. Há dados que nos levam a sustentar que a associação seja mesmo com a notícia do Carnaval, como exposto anteriormente. Um primeiro dado a sustentar 
essa visão é a proximidade com o feriado e com as postagens feitas pelo presidente brasileiro. Parte-se do princípio de que o gênero, quando veiculado pela imprensa tenderia a repercutir uma informação recente, do dia (na internet) ou mesmo da véspera (caso dos jornais impressos).

Essa proximidade com o fato é ainda mais ágil nos ambientes digitais, que permitem difundir visualmente (por charges ou outros gêneros multimodais) uma notícia em minutos, quando não segundos após ela ocorrer. Embora não seja o foco específico desta discussão, cabe o registro de memes que circulam em redes sociais concomitantemente um fato compartilhado coletivamente ocorre, como uma transmissão de jogo de futebol, um programa de TV ou uma transmissão de cerimônia de premiação, como a do Oscar, nos Estados Unidos, que premia filmes e profissionais relacionados à indústria do cinema.

Outro argumento é que, por mais que se autorize outra leitura, há um elemento que externo que explicita a intenção de Benett. Embora isso não estivesse exposto verbalmente no Facebook, ele deixou esse dado claro na postagem da mesma charge no Instagram. Nesta rede social, o cartunista incluiu, após a figura, hashtags que criavam uma associação temática ao conteúdo apresentado, como visto a seguir:
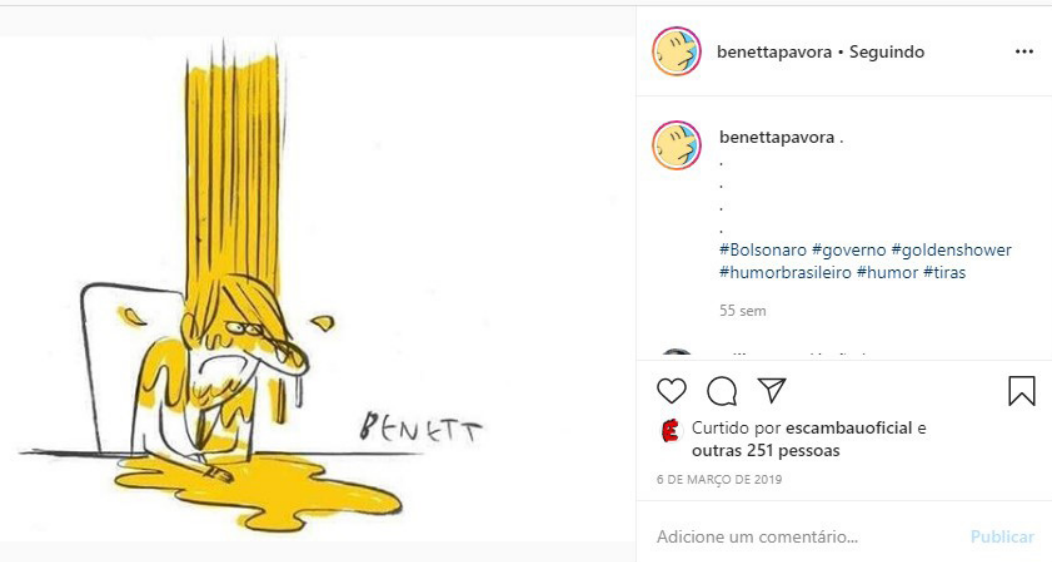

Fig. 8 - Postagem de charge no Instagram

Fonte: Benett (06/03/2019)

Sistematizando, foram inseridas seis hashtags: \#Bolsonaro; \#governo; \#goldenshower; \#humorbrasileiro; \#humor; \#tiras. O recurso é uma estratégia para criar uma espécie de indexador de temas. Quando 
o tópico é antecedido pelo sinal gráfico, ele fica automaticamente azul - assim como na escrita dos nomes de outros usuários - e serve para vincular todas as postagens daquela rede social que abordaram o assunto. Serve também, neste caso, como uma forma de expor um conjunto de palavras-chave, que ajudariam no processo do sentido. $\mathrm{O}$ leitor seria auxiliado a ver no desenho uma representação do presidente (\#Bolsonaro), vitimado pelo episódio do fetiche sexual (\#goldenshower) e mostrado em uma situação que procurava, intencionalmente, criar um efeito de humor (\#humorbrasileiro; \#humor).

Houve 252 curtidas na postagem, mas poucas manifestações de leitores nos comentários, seis ao todo. Uma expunha um ponto de vista negativo sobre o caso envolvendo o político (rotulado ironicamente como "ser supremo"), outra elogiava o trabalho ("sensacional"), três sugeriam outras hashtags (dois propuseram "\#Bolsomijo" e um, "chorabolsolixo") e uma expunha uma onomatopeia de risos ("Kkkkkkk"). Nas duas últimas, há marcas de que a o trabalho gráfico foi, de fato, lido como uma produção humorística (como depreendido pela onomatopeia) e vinculado ao golden shower (pelo uso do termo "mijo" na hashtag).

\section{CONSIDERAÇÕES FINAIS}

Dezesseis dias depois de pôr no ar o vídeo com o ato de golden shower, Jair Bolsonaro retirou a imagem de sua conta no Twitter. Segundo se noticiou à época, isso ocorreu após a dupla mostrada no vídeo compartilhado pelo presidente ter entrado com mandado de segurança junto ao Supremo Tribunal Federal pedindo que a postagem fosse eliminada. O gesto não apagou, no entanto, a repercussão do caso, tanto no noticiário quanto nas charges.

Parte dos desenhos humorísticos produzida no período se ancorou, como visto, no uso do amarelo como recurso para aludir visualmente ao fato. A estratégia dos autores era se valer da cor para trazer à tona o caso. Caberia aos leitores, por meio do acionamento da memória sobre o episódio, ainda recente naqueles dias de Carnaval de 2019, período em que os trabalhos gráficos foram veiculados. Esse apoio no aspecto cognitivo, somado ao entorno cultural de onde a cor circula, compõe elemento central para a compreensão, segundo defende Silveira (2015).

Do ponto de vista de uso da cor para a produção do sentido, os chargistas se valeram de estratégias comuns. O primeiro mecanismo utilizado foi a apropriação de um signo plástico, conforme nomenclatura adotada pelo Grupo $\mu$, com o intuito de fazer com que ele transmita ao 
leitor uma informação, a de que aquele conteúdo representava urina. A vinculação da cor com a informação nos textos veiculados pela imprensa, como visto, é um dos postulados centrais de Guimarães (2000, 2003).

Esses elementos deram algumas das pistas ao leitor para que entendesse a crítica carregada nas charges, mesmo que elas não explicitassem o fato, como ocorreu no exemplo da charge aqui trabalhado. A compreensão, portanto, passava necessariamente pela leitura e entendimento dos sentidos (compor urina e estar vinculado ao caso golden shower) trazidos pelo amarelo. Ao mesmo tempo, exercia o gatilho necessário para a composição do script inesperado, que levaria ao humor, tal qual postulado por Attardo e Raskin (1991).

Encerra-se reprisando a proposta deste artigo: destacar que, além dos elementos imagéticos e verbais escritos, a cor pode desempenhar papel relevante no processo de composição das histórias gráficas e de produção de sentido delas, incluído aí o humorístico. É algo que tende a ficar em segundo plano. Mas, a depender do caso, é tão essencial quanto as figuras em si.

\section{REFERÊNCIAS}

ARBACH, J. M. I. O fato gráfico: o humor gráfico como gênero jornalístico. 249 f. Tese (Doutorado em Comunicação). Escola de Comunicações e Artes, Universidade de São Paulo. São Paulo, 2007. Disponível em: <https://www.teses.usp.br/teses/ disponiveis/27/27153/tde-22072009-182433/pt-br.php>. Acesso em: 30 mai. 2020.

ATTARDO, S.; RASKIN, V. Script theory revis(it)ed: joke similarity and joke representation model. Humor: International Journal of Humor Research, Berlin/New York: Mouton de Gruyter, vol. 4-3/4, p. 293-347, 1991.

BARTON, D.; LEE, C. Linguagem online. Trad. Milton Camargo Mota. São Paulo: Parábola Editorial, 2015.

BENETT, A. Benett. Facebook. 6 mar. 2019. Disponível em:

$<$ https://www.facebook.com/paginadoBenett/photos/a.678427755567245/2078409508 902389/?type=3\&theater $>$. Acesso em: 30 mai. 2020.

BENETT, A. benettapavora. Instagram. 6 mar. 2019. Disponível em: <https://www. instagram.com/p/BurHVeHgvXS/>. Acesso em: 30 mai. 2020.

BENETT, A. 30 charges de Benett para os 100 dias de Bolsonaro. Plural. Curitiba: abr. 2019. Disponível em: <https://www.plural.jor.br/charges/bennet/30-charges-de-benettpara-os-100-dias-de-bolsonaro/>. Acesso em: 30 mai. 2020. 
BOLSONARO, J. M. Twitter. 5 mar. 2019, 20h08. Disponível em: <https://twitter.com/ jairbolsonaro>. Acesso em: 30 mai. 2020.

BOLSONARO, J. M. Twitter. 6 mar. 2019, 9h26. Disponível em: <https://twitter.com/ jairbolsonaro>. Acesso em: 30 mai. 2020.

BRAGON, R.; MATTOSO, C. Ministro de Bolsonaro criou candidatos laranjas para desviar recursos na eleição. Folha de S.Paulo. São Paulo, 4 fev. 2019. Disponível em: $\quad<$ https://www1.folha.uol.com.br/poder/2019/02/ministro-de-bolsonaro-crioucandidatos-laranjas-para-desviar-recursos-na-eleicao.shtml>. Acesso em: 30 mai. 2020.

CAVALCANTE, M. M.; CUSTÓDIO FILHO, V.; BRITO, M. A. P. Coerência, referenciação e ensino. São Paulo: Cortez, 2014.

CAVALCANTI, L. H. Historias del humor gráfico en Brasil. Lleida, Espanha: Editorial Milenio, 2005.

CHARGE ONLINE. Disponível em: <https://www.chargeonline.com.br/>. Acesso em: 30 mai. 2020.

ELIAS, V. M. HQ e leitura na mídia social digital: porque comentar é preciso. In: LINS, M. P. P.; CAPISTRANO JR., R. (Orgs.). Quadrinhos sob diferentes olhares. Vitória: PPGELUFES, 2014. p. 45-64.

ELIAS, V. M. Linguística Textual e estudos do hipertexto: focalizando o conceito e a coerência. In: CAPISTRANO JR., R.; LINS, M. P. P.; ELIAS, V. M. (Orgs.). Linguística Textual: diálogos interdisciplinares. São Paulo: Labrador, 2017. p. 317-338.

GIL, C. M. C. A linguagem da surpresa: uma proposta para o estudo da piada. 220 f. Tese (Doutorado em Letras Clássicas e Vernáculas). Faculdade de Filosofia, Letras e Ciências Humanas, Universidade de São Paul, São Paulo, 1991.

GRUPO $\mu$. 1993. Tratado del signo visual: para una retórica de la imagen. Madrid: Cátedra, 1993.

GUIMARÃES, L. A cor como informação: a construção biofísica, linguística e cultural da simbologia das cores. São Paulo: Annablume, 2000.

GUIMARÃES, L. As cores da mídia: a organização da cor-informação no jornalismo. São Paulo: Annablume, 2003.

$\mathrm{KOCH}$, I. G. V.; BENTES, A. C.; CAVALCANTE, M. M. Intertextualidade: diálogos possíveis. São Paulo: Cortez, 2007.

MARINGONI, G. Angelo Agostini: a imprensa ilustrada da Corte à Capital Federal, 1864-1910. São Paulo: Devir, 2011. 
MATTOSO, C.; BRAGON, R.; SUAREZ, J. Partido de Bolsonaro criou candidata laranja para usar verba pública de R\$ 400 mil. Folha de S.Paulo. São Paulo, 10 fev. 2019. Disponível em: <https://www1.folha.uol.com.br/poder/2019/02/partido-de-bolsonarocriou-candidata-laranja-para-usar-verba-publica-de-r-400-mil.shtml>. Acesso em: 30 mai. 2020.

MEDIA 1. Tenor. 6 mar. 2019. Disponível em:

<https://media1.tenor.co/images/bb7e888012206d10c5dba135e6a6e344/tenor. gif?itemid=4897758>. Acesso em: 30 mai. 2020.

MUNIZ, K. S. Piadas: conceituação, constituição e práticas - Um estudo de um gênero. 149 f. Dissertação (Mestrado em Linguística). Instituto de Estudos da Linguagem, Universidade Estadual de Campinas. Campinas, SP, 2004. Disponível em:

$<$ http://taurus.unicamp.br/bitstream/REPOSIP/270788/1/Muniz_Kassandra_M.pdf>. Acesso em: 30 mai. 2020.

OLIVEIRA, M. R. Interações na blogosfera. In: SHEPERD, T. G; SALIÉS, T. G. (Orgs.). Linguística da internet. São Paulo: Contexto, 2013. p. 157-179.

RAMOS, P. Faces do humor: uma aproximação entre piadas e tiras. Campinas, SP: Zarabatana Books, 2011.

RAMOS, P. Piadas para ver: o uso da imagem como recurso de humor em tiras cômicas. In: CARMEliNO, A. C. (Org.). Humor: eis a questão. São Paulo: Cortez, 2015. p. 137156.

RASKIN, V. Semantic mechanisms of humor. Holland: Dordrecht, D. Reidel Publishing Company, 1985.

RIANI-COSTA, C. F. Linguagem \& cartum... tá rindo do quê? Um mergulho nos salões de humor de Piracicaba. 182 f. Dissertação (Mestrado em Comunicação Social). Universidade Metodista de São Paulo, São Bernardo do Campo, SP, 2001.

ROMUALDO, E. Charge jornalística: intertextualidade e polifonia. Maringá, PR: Eduem, 2000.

SERRA E GURGEL, J. B. Dicionário de gíria-modismo linguístico: o equipamento falado do brasileiro. Brasília: ed. do autor, 1998.

SILVEIRA, L. M. Introdução à teoria da cor. 2. ed. Curitiba: Editora da UTFPR, 2015

Recebido em: 05/06/2020

Aceite em: $\quad$ 15/06/2020. 